\title{
ON THE METRIC DIMENSION OF DIRECTED AND UNDIRECTED CIRCULANT GRAPHS
}

\author{
TOMÁš VETRÍK \\ Department of Mathematics and Applied Mathematics \\ University of the Free State \\ Bloemfontein, South Africa \\ e-mail: vetrikt@ufs.ac.za
}

\begin{abstract}
The undirected circulant graph $C_{n}( \pm 1, \pm 2, \ldots, \pm t)$ consists of vertices $v_{0}, v_{1}, \ldots, v_{n-1}$ and undirected edges $v_{i} v_{i+j}$, where $0 \leq i \leq n-1,1 \leq j \leq t$ $\left(2 \leq t \leq \frac{n}{2}\right)$, and the directed circulant graph $C_{n}(1, t)$ consists of vertices $v_{0}, v_{1}, \ldots, v_{n-1}$ and directed edges $v_{i} v_{i+1}, v_{i} v_{i+t}$, where $0 \leq i \leq n-1(2 \leq$ $t \leq n-1)$, the indices are taken modulo $n$. Results on the metric dimension of undirected circulant graphs $C_{n}( \pm 1, \pm t)$ are available only for special values of $t$. We give a complete solution of this problem for directed graphs $C_{n}(1, t)$ for every $t \geq 2$ if $n \geq 2 t^{2}$. Grigorious et al. [On the metric dimension of circulant and Harary graphs, Appl. Math. Comput. 248 (2014) 47-54] presented a conjecture saying that $\operatorname{dim}\left(C_{n}( \pm 1, \pm 2, \ldots, \pm t)\right)=t+p-1$ for $n=2 t k+t+p$, where $3 \leq p \leq t+1$. We disprove it by showing that $\operatorname{dim}\left(C_{n}( \pm 1, \pm 2, \ldots, \pm t)\right) \leq t+\frac{p+1}{2}$ for $n=2 t k+t+p$, where $t \geq 4$ is even, $p$ is odd, $1 \leq p \leq t+1$ and $k \geq 1$.
\end{abstract}

Keywords: metric dimension, resolving set, circulant graph, distance.

2010 Mathematics Subject Classification: 05C35, 05C12.

\section{REFERENCES}

[1] A. Borchert and S. Gosselin, The metric dimension of circulant graphs and Cayley hypergraphs, Util. Math. 106 (2018) 125-147.

[2] G. Chartrand, L. Eroh, M.A. Johnson and O.R. Oellermann, Resolvability in graphs and the metric dimension of a graph, Discrete Appl. Math. 105 (2000) 99-113. doi:10.1016/S0166-218X(00)00198-0

[3] K. Chau and S. Gosselin, The metric dimension of circulant graphs and their Cartesian products, Opuscula Math. 37 (2017) 509-534. doi:10.7494/OpMath.2017.37.4.509 
[4] C. Grigorious, P. Manuel, M. Miller, B. Rajan and S. Stephen, On the metric dimension of circulant and Harary graphs, Appl. Math. Comput. 248 (2014) 47-54. doi:10.1016/j.amc.2014.09.045

[5] M. Imran, On the metric dimension of barycentric subdivision of Cayley graphs, Acta Math. Appl. Sin. Eng. Ser. 32 (2016) 1067-1072. doi:10.1007/s10255-016-0627-0

[6] M. Imran, A.Q. Baig, S.A. Ul. Hag Bokhary and I. Javaid, On the metric dimension of circulant graphs, Appl. Math. Lett. 25 (2012) 320-325. doi:10.1016/j.aml.2011.09.008

[7] I. Javaid, M.N. Azhar and M. Salman, Metric dimension and determining number of Cayley graphs, World Appl. Sci. J. 18 (2012) 1800-1812.

[8] I. Javaid, M.T. Rahim and K. Ali, Families of regular graphs with constant metric dimension, Util. Math. 75 (2008) 21-33.

[9] S. Khuller, B. Raghavachari and A. Rosenfeld, Landmarks in graphs, Discrete Appl. Math. 70 (1996) 217-229. doi:10.1016/0166-218X(95)00106-2

[10] R.A. Melter and I. Tomescu, Metric bases in digital geometry, Comput. Vision Graphics Image Process. 25 (1984) 113-121. doi:10.1016/0734-189X(84)90051-3

[11] M. Salman, I. Javaid and M.A. Chaudhry, Resolvability in circulant graphs, Acta Math. Sin. Eng. Ser. 28 (2012) 1851-1864. doi:10.1007/s10114-012-0417-4

[12] S.W. Saputro, R. Simanjuntak, S. Uttunggadewa, H. Assiyatun, E.T. Baskoro, A.N.M. Salman and M. Bača, The metric dimension of the lexicographic product of graphs, Discrete Math. 313 (2013) 1045-1051. doi:10.1016/j.disc.2013.01.021

[13] T. Vetrík, The metric dimension of circulant graphs, Canad. Math. Bull. 60 (2017) 206-216.

doi:10.4153/CMB-2016-048-1

Received 25 May 2017

Revised 23 January 2018

Accepted 23 January 2018 